\title{
Perceptions, Attitudes, Behaviors, and Barriers to Effective Obesity Care in South Korea: Results from the ACTION-IO Study
}

\author{
Soo Lim', Bumjo Oh², Seung-Hwan Lee ${ }^{3}$, Yang-Hyun $\mathrm{Kim}^{4}$, Yousun Ha ${ }^{5}$, Jae-Heon Kang ${ }^{6, *}$ \\ ${ }^{1}$ Department of Internal Medicine, Seoul National University Bundang Hospital, Seoul National University College of Medicine, Seongnam; ${ }^{2}$ Department of Family \\ Medicine, SMG-SNU Boramae Medical Center, Seoul; ${ }^{3}$ Division of Endocrinology and Metabolism, Department of Internal Medicine, Seoul St. Mary's Hospital, \\ College of Medicine, The Catholic University of Korea, Seoul; ${ }^{4}$ Department of Family Medicine, Korea University Anam Hospital, Korea University College of Medicine, \\ Seoul; ${ }^{5}$ Novo Nordisk, Seoul; ${ }^{6}$ Department of Family Medicine, Kangbuk Samsung Hospital, Sungkyunkwan University School of Medicine, Seoul, Korea
}

Background: The prevalence of obesity is increasing in South Korea. We aimed to identify the perceptions, attitudes, behaviors, and barriers to effective obesity care in South Korea.

Methods: The Awareness, Care, and Treatment In Obesity maNagement-an International Observation (ACTION-IO) study was a cross-sectional survey conducted in 11 countries. Respondents were people with obesity (PwO; body mass index $\geq 25 \mathrm{~kg} / \mathrm{m}^{2}$ in South Korea from self-reported height/weight) and healthcare professionals (HCPs) primarily involved in direct care with PwO.

Results: The survey was completed by 1,500 PwO and $200 \mathrm{HCPs}$ in South Korea. PwO (78\%) and HCPs (81\%) agreed that obesity is a chronic disease, but more PwO (84\%) believed that obesity has an extreme impact on their overall health compared with HCPs (65\%). Most PwO felt completely responsible for their own weight loss (81\%), and $78 \%$ reported at least one serious weight loss attempt in the past. In contrast, HCPs reported that, on average, only $35 \%$ of their patients with obesity had made a serious attempt at losing weight. Only $31 \%$ of PwO had discussed weight with their HCP in the past 5 years; of those, $78 \%$ appreciated that HCPs initiated these conversations. Short appointment times restricted weight loss discussions for $70 \%$ of HCPs, and $29 \%$ of HCPs expressed complete comfort with such conversations.

Conclusion: South Korean PwO are motivated to lose weight and have expressed interest in HCPs being more active in their weight management. Further nationwide efforts may be required to lower the barriers to education about obesity and effective weight loss discussion and management.

Key words: Obesity, Obesity management, Social perception, Comorbidity, Korea

\author{
Received January 22, 2020 \\ Reviewed February 18, 2020 \\ Accepted April 26, 2020 \\ ${ }^{*}$ Corresponding author \\ Jae-Heon Kang \\ https://orcid.org/0000-0002-5209-0824 \\ Department of Family Medicine, \\ Kangbuk Samsung Hospital, \\ Sungkyunkwan University School of \\ Medicine, 29 Saemunan-ro, Jongno-gu, \\ Seoul 03181, Korea \\ Tel: +82-2-2001-2797 \\ Fax: +82-2-2001-2670 \\ E-mail: jaeheon.kang@samsung.com
}

\section{INTRODUCTION}

Globally, the prevalence of obesity has risen dramatically over the past few decades and it is now a significant contributor to poor health and quality of life. ${ }^{1,2}$ Like many developed countries, South Korea is currently facing an increase in obesity rates. ${ }^{2}$ Current estimates indicate that nearly one-third of South Koreans have obesity according to the criteria specific to Asians. ${ }^{2,3}$ If current trends re- main unabated, $62 \%$ of men and $37 \%$ of women in South Korea will have obesity by $2030 .^{3}$

In South Korea, recent guidelines define adult obesity as a body mass index (BMI) of $\geq 25 \mathrm{~kg} / \mathrm{m}^{2}{ }^{4}$ For people with obesity ( $\mathrm{PwO}$ ), the Korean Society for the Study of Obesity (KSSO) recommends $5 \%$ to $10 \%$ weight loss within 6 months of diagnosis. ${ }^{4}$ Lifestyle interventions such as reduced food intake, increasing physical activity, and behavioral therapy are the first lines of treatment recommend- 
ed by the KSSO. ${ }^{4}$ Pharmacologic treatment is an option for $\mathrm{PwO}$ who have been unsuccessful in their weight loss attempts using lifestyle modification. ${ }^{4}$ Bariatric surgery is considered only for $\mathrm{PwO}$ with BMI $\geq 35 \mathrm{~kg} / \mathrm{m}^{2}$ (obesity class III) or with BMI $\geq 30 \mathrm{~kg} / \mathrm{m}^{2}$ and presence of obesity-related comorbidities. ${ }^{4}$

Despite the endorsement of evidence-based policy guidelines, the rising rates of obesity across South Korea suggests poor implementation or outcomes from such recommendations. In other words, the availability of guidelines does not appear to guarantee obesity care of a consistent quality. ${ }^{5}$ At present, there are limited studies investigating how $\mathrm{PwO}$ and healthcare professionals ( $\mathrm{HCPs}$ ) treat obesity in South Korea. ${ }^{6}$

The aim of the Awareness, Care, and Treatment In Obesity maNagement-an International Observation (ACTION-IO) study was to identify the perceptions, attitudes, behaviors, and potential barriers to effective obesity care across $\mathrm{PwO}$ and HCPs; the primary global results have been reported previously. ${ }^{5}$ The objective of this report was to present the results from the ACTION-IO survey of $\mathrm{PwO}$ and HCPs in South Korea and to identify perceptions, attitudes, behaviors, and barriers that may inform South Korean obesity care.

\section{METHODS}

\section{Study design and participants}

The ACTION-IO study was a cross-sectional, non-interventional, descriptive study that collected data via an online survey among $\mathrm{PwO}$ and HCPs across 11 countries: Australia, Chile, Israel, Italy, Japan, Mexico, Saudi Arabia, South Korea, Spain, the United Arab Emirates, and the United Kingdom. South Korean PwO and HCPs completed the survey between August 14, 2018 and September 20, 2018. Methodology for the ACTION-IO study has been reported previously. ${ }^{5}$ Electronic informed consent was provided by all respondents prior to initiation of the screening questions and survey. A local ethics/Institutional Review Board approved the questionnaires (IRB No. PAIK 2018-06-011-003). The study was conducted in accordance with the Guidelines for Good Pharmacoepidemiology Practices ${ }^{7}$ and was registered under the ClincalTrials.gov number NCT03584191.

Eligible South Korean $\mathrm{PwO}$ were $\geq 18$ years old with a current
BMI of $\geq 25 \mathrm{~kg} / \mathrm{m}^{2}$, calculated based on self-reported weight and height. Key exclusion criteria included pregnancy, participation in intense fitness or body building programs, or significant unintentional weight loss in the 6 months prior to completing the survey.

Eligible HCPs were medical practitioners with $\geq 2$ years of experience who spend $\geq 70 \%$ of their time involved in direct patient care and had seen $\geq 100$ patients during the past month, with $\geq 10$ of whom having a BMI of $\geq 25 \mathrm{~kg} / \mathrm{m}^{2}$. HCPs specializing in general, plastic, or bariatric surgery were excluded.

In the Results, "PwO" refers to the general population of people who qualified for the study and completed the survey and who may or may not have seen an HCP about their weight; "patients" refers to the HCPs' populations of patients who have obesity, and on whom the HCPs based their survey answers.

\section{Survey development and procedures}

The two questionnaires directed at $\mathrm{PwO}$ or HCPs were developed by an international steering committee of medical professionals and leading experts in obesity and psychology from the participating countries, including three medical doctors employed by the sponsor (Novo Nordisk, Bagsværd, Denmark). KJT Group (Honeoye Falls, NY, USA) conducted the online survey (Decipher Survey Software, FocusVision Worldwide Inc., Stamford, CT, USA) and managed the acquisition and analysis of data.

South Korean $\mathrm{PwO}$ and HCPs were recruited through email where possible; telephone or in-person recruitment was also used for HCPs. Respondents completed the survey in Korean. All participants were blinded to the study goals and were informed the intention of the survey was "to determine treatment experiences of patients with a specific condition."

\section{Objectives and outcomes}

The primary objectives were to identify the perceptions, attitudes, and behaviors of PwO and HCPs, and to uncover the barriers to effective obesity care. The objectives were measured by single-item selection (including response to weight loss discussions), multiple-item selection (including weight loss motivators, effective weight loss methods, and types of weight management goals), numeric responses (including proportion of $\mathrm{PwO}$ who made a serious weight loss effort), end-anchored 5-point Likert agreement 
scales (including attitudes toward obesity, attitudes toward prescription weight loss medication and surgery, and weight loss barriers), and by ranking (including top factors for improving weight loss outcomes).

\section{Statistical analysis}

Deidentified data were summarized and analyzed using descriptive statistics (means, medians, frequencies) using IBM SPSS ver. 23.0 (IBM Corp., Armonk, NY, USA), Stata version IC 14.2 (StataCorp., College Station, TX, USA), and Excel version 2016 (Microsoft, Redmond, WA, USA). The full data is available as Supplementary Materials.

\section{RESULTS}

\section{Demographics}

The ACTION-IO survey was completed by 1,500 $\mathrm{PwO}$ and 200 HCPs in South Korea, with a mean completion time of 22 minutes for PwO and 27 minutes for HCPs (Table 1, Supplementary Table 1).

\section{Perceptions of obesity}

Results from the survey indicated that although the perception of obesity as a chronic disease was similar between the groups PwO, 78\% vs. HCPs, 81\% (Supplementary Fig. 1), a lower proportion of HCPs $(65 \%)$ believed that obesity has a large impact on overall health compared with PwO (84\%) (Supplementary Fig. 2). In contrast, many HCPs (77\%-93\%) viewed diseases like diabetes, stroke, cancer, or chronic obstructive pulmonary disease to have a large impact on health (Supplementary Fig. 2).

\section{Barriers to weight loss and $\mathrm{PwO}-\mathrm{HCP}$ interactions}

Most $\mathrm{PwO}(81 \%)$ assumed full responsibility for their weight loss, while $32 \%$ of HCPs placed this responsibility on $\mathrm{PwO}$ (Fig. 1, item 1). Few $\mathrm{PwO}$ (36\%) felt that this responsibility rested on their HCP (Fig. 1, item 7); on the other hand, most HCPs (79\%) acknowledged their responsibility for their patients' weight loss efforts (Fig. 1, item 7).

A similar proportion of $\mathrm{PwO}$ (61\%) and HCPs (66\%) considered lifestyle as a key factor for the struggle with obesity (Fig. 1,
Table 1. Sample demographics and characteristics

\begin{tabular}{|c|c|c|}
\hline Variable & $\operatorname{Pw0}(n=1,500)$ & $\mathrm{HCP}(\mathrm{n}=200)$ \\
\hline Age (yr) & $40(18-81)$ & $47(26-74)$ \\
\hline \multicolumn{3}{|l|}{ Sex } \\
\hline Male & $908(61)$ & $176(88)$ \\
\hline Female & $592(39)$ & $24(12)$ \\
\hline \multicolumn{3}{|l|}{ BMI classification* } \\
\hline Respondent & $1,500(100)$ & $200(100)$ \\
\hline $\mathrm{BMl}<25 \mathrm{~kg} / \mathrm{m}^{2}$ & 0 & $152(76)$ \\
\hline Obesity class I (25-29.9 kg/m²) & $1,190(79)$ & $44(22)$ \\
\hline Obesity class II (30-34.9 kg/m²) & $221(15)$ & $4(2)$ \\
\hline Obesity class III (35-39.9 kg/m²) & $45(3)$ & 0 \\
\hline Obesity class IV ( $\geq 40$ kg/m²) & $44(3)$ & 0 \\
\hline \multicolumn{3}{|l|}{ Number of comorbidities* } \\
\hline 0 & 597 (32) & NA \\
\hline 1 & $403(30)$ & NA \\
\hline 2 & $262(18)$ & NA \\
\hline 3 & $132(11)$ & NA \\
\hline$\geq 4$ & $106(8)$ & NA \\
\hline \multicolumn{3}{|l|}{ HCP category } \\
\hline $\mathrm{PCP}$ & NA & $100(50)$ \\
\hline Specialist & NA & $100(50)$ \\
\hline Diabetologist/endocrinologist & NA & $40(20)$ \\
\hline Cardiologist & NA & $33(17)$ \\
\hline Internal medicine (non-PCP) & NA & 0 \\
\hline Gastroenterologist & NA & $24(12)$ \\
\hline Bariatrics/obesity medicine $^{\dagger}$ & NA & $3(2)$ \\
\hline \multicolumn{3}{|l|}{ Obesity specialist ${ }^{\ddagger}$} \\
\hline Yes & NA & 155 (78) \\
\hline No & NA & $45(22)$ \\
\hline
\end{tabular}

Values are presented as mean (range) or number (\%).

*Values are reported for the final unweighted sample except for the Pw0 characteristics which represent weighted percentages; 'Bariatric surgeons were ineligible per prespecified protocol criteria; ${ }^{\ddagger} A$ physician who selected at least one of the following criteria was considered to be an obesity specialist: $50 \%$ or more of their patients are seen for obesity or weight management; they reported having advanced/formal training in the treatment of obesity or weight management beyond medical school; they consider themselves to be an expert in obesity or weight loss management; or they work in an obesity service clinic.

PwO, people with obesity; $\mathrm{HCP}$, healthcare professional; BMI, body mass index; NA, not applicable; PCP, primary care physician.

item 2). Unhealthy eating habits ( $\mathrm{PwO}, 64 \%$; HCPs, 87\%) and lack of exercise ( $\mathrm{PwO}, 78 \%$; HCPs, 88\%) were also recognized as additional barriers to weight loss (Supplementary Fig. 3). Compared with HCPs (65\%), only a small proportion of PwO (29\%) considered genetics to be a contributor to obesity (Supplementary Fig. 3). While about two-thirds of HCPs suggested that their patients' inadequate knowledge of obesity is a barrier to weight loss, only $20 \%$ of $\mathrm{PwO}$ acknowledged their poor understanding in their 


\section{Attitudes towards obesity}

1a. My weight loss is completely my responsibility 1b. My patients' weight loss is completely their responsibility

2a. For me to lose weight, I would need to completely change my lifestyle 2b. For my patients to lose weight, they would need to completely change their lifestyles 3a. I am motivated to lose weight 3b. My patients are motivated to lose weight

4a. I know how to keep the weight off 4b. My patients know how to keep the weight off

5a. I could lose weight if I really set my mind to it 5b. My patients could lose weight if they really set their mind to it

Cy patients know whichos

6a. I know how to lose weight

7a. My HCP has a responsibility to actively contribute to a successful weight loss effort 7b. I have a responsibility to actively contribute to my patients' weight loss effort

8a. I do not feel comfortable bringing up my weight unless my HCP mentions it first 8b. I do not feel comfortable bringing up my patients' weight unless they mention if first

9a. I am past the point where I can lose weight on my own 9b. My patients are past the point where they can lose weight on their own

10a. If I lost weight, it would be easy for me to keep the weight off 10b. If my patients lost weight, it would be easy for them to keep the weight off

11a. There is nothing my doctor can do to help me manage my weight $11 \mathrm{~b}$. There is nothing I can do to help patients manage their weight

12a. Obesity is less important to me than other diseases $12 \mathrm{~b}$. Obesity is less important to me than many of other diseases I treat

13a. It is easy for me to lose weight 13b. It is easy for my patients to lose weight

14a. I am happy with my current weight 14b. My patients are happy with their current weight
Percentage of respondents in agreement with statement (top 2)

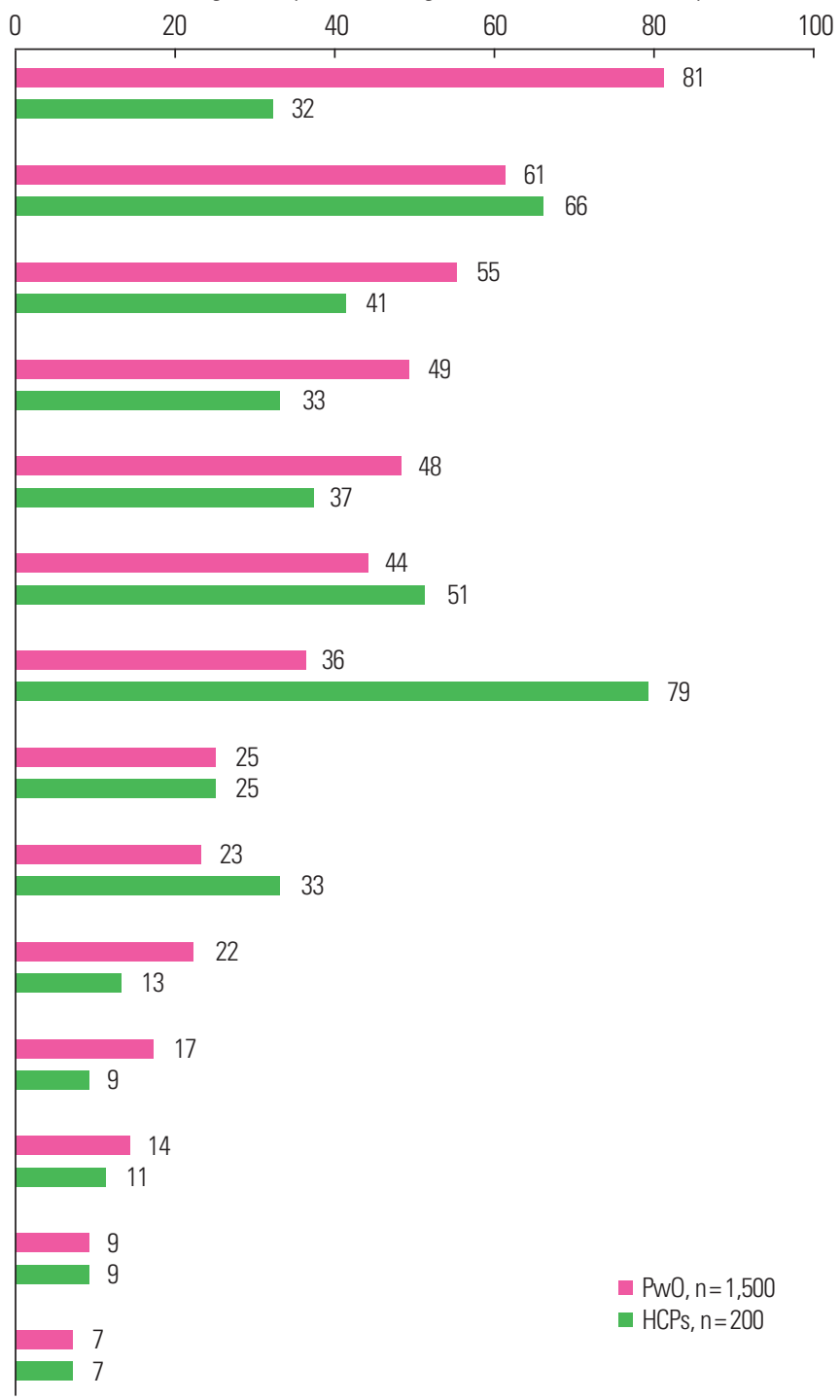

Figure 1. Proportion of people with obesity (PwO) and healthcare professionals (HCPs) in Korea who agree with the statements shown regarding attitudes towards obesity. Those in agreement selected rating 4 or 5 (top 2 scores), where $5=$ completely agree and $1=$ do not agree at all.

struggles with this disease (Supplementary Fig. 3). Furthermore, compared with HCPs (42\%), fewer PwO (12\%) regarded financial status as a weight loss barrier (Supplementary Fig. 3).

Although 55\% of PwO were motivated to lose weight, only $41 \%$ of HCPs acknowledged the motivation for weight loss expressed by $\mathrm{PwO}$ (Fig. 1, item 3). Indeed, a majority of $\mathrm{PwO}$ were intending to lose weight since few $\mathrm{PwO}(19 \%)$ reported having no plans for weight loss within the following 6 months (Supplementary Fig. 4). While $78 \%$ of $\mathrm{PwO}$ reported at least one serious weight loss at- tempt in the past (Fig. 2A), HCPs reported that, on average, only $35 \%$ of their patients had made a serious weight loss effort (Fig. 2B). HCPs reported that only $39 \%$ of their patients who they deemed to have made a serious weight loss effort were successful (data not shown).

\section{Attitudes and behaviors towards weight loss}

Concerning their attitudes towards weight loss, $48 \%$ of $\mathrm{PwO}$ believed that they could lose weight if they set their mind to it (Fig. 1, 
A

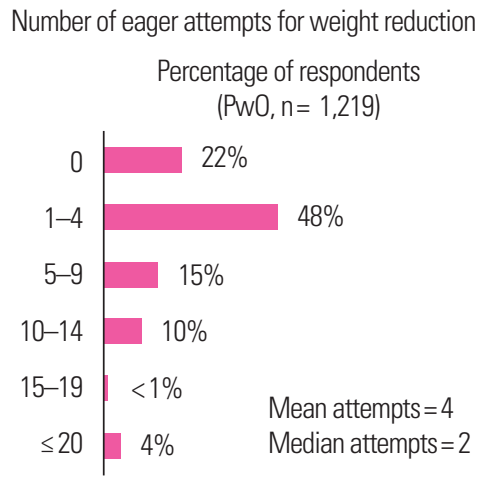

B

Proportion of patients with eager attempts for weight reduction

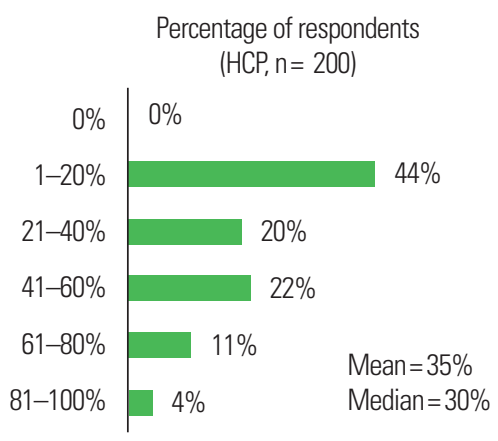

C Degree and duration of attempts for weight reduction in last 3 years at threshold of $10 \%$ (Pw0, $n=1,500)$

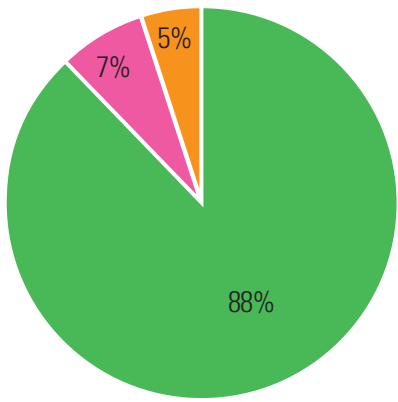

- No weight loss or $<10 \%$ weight loss in last 3 years

a $\geq 10 \%$ weight loss in last 3 years, maintained for $<1$ year

a $\geq 10 \%$ weight loss in last 3 years, maintained for 1 year or more

Data calculated from responses to 020 and 022

Figure 2. Serious weight loss efforts made and people with obesity (PwO) response to weight loss efforts in Korea. (A) Number of serious past weight loss efforts as reported by PwO in Korea. (B) Proportion of patients who have made serious weight loss efforts as reported by healthcare professionals (HCPs) in Korea. (C) Proportion of PwO in Korea who reported a weight loss of at least $10 \%$ in the last 3 years and who maintained the weight loss for at least 1 year. 0 , survey question.

item 5); however, many $\mathrm{PwO}$ reported struggling to lose weight and maintain weight loss (Fig. 2C). Only $12 \%$ of $\mathrm{PwO}$ reported a weight loss of at least $10 \%$ body weight over the past 3 years, and within this proportion, only $46 \%$ could maintain the weight loss for at least 1 year (5\% of PwO in total) (Fig. 2C, Supplementary Fig. 5).

South Korean $\mathrm{PwO}$ started struggling with their weight at an average age of 39 years. Rather than seeking advice from HCPs (19\%), $\mathrm{PwO}$ preferred alternative sources of information regarding weight management, such as the internet (54\%), family and friends (37\%), TV programs (32\%), and smartphone apps (32\%) (Supplementary Fig. 6). In the past 5 years, only $31 \%$ of $\mathrm{PwO}$ discussed weight with an $\mathrm{HCP}$ (Fig. 3A), and for these $\mathrm{PwO}$, there was a mean 1-year gap between first acknowledging their struggle with obesity and their initial discussion with an HCP regarding weight (Fig. 3B). When discussing obesity, $31 \%$ of $\mathrm{PwO}$ reported initiating the conversation themselves, while HCPs in turn reported that $48 \%$ of their patients initiated the conversation (Supplementary Fig. 7). The patient's BMI was the most common criteria selected by HCPs for starting a weight management discussion (Supplementary Fig. 8). Furthermore, only $29 \%$ of HCPs expressed they were very or extremely comfortable with having discussions about weight with their patients (Supplementary Fig. 9).

\section{Weight loss discussions}

Many $\mathrm{PwO}$ (70\%) who had a weight management discussion with an HCP in the past 5 years had been diagnosed with obesity (22\% of PwO in total) (Fig. 3A). On average, HCPs informed 68\% of their patients about a diagnosis of obesity; however, $2 \%$ of HCPs never informed their patients of the diagnosis (Supplementary Fig. 10; data not shown). HCPs scheduled follow-up appointments for $42 \%$ of their patients, of whom $44 \%$ reportedly kept these appointments always or most of the time (Supplementary Fig. 11). Strikingly, the same question posed to $\mathrm{PwO}$ yielded only $23 \%$ of patients having had a follow-up appointment scheduled after the weight management discussion with their HCP (7\% of $\mathrm{PwO}$ in total) (Fig. 3A). Many $\mathrm{PwO}$ (92\%) reported that they have attended or are planning to attend their follow-up appointment, if scheduled (Supplementary Fig. 12).

When assessing their weight management discussion with HCPs, $17 \%$ of $\mathrm{PwO}$ found the conversation very or extremely helpful (Supplementary Fig. 13). Additionally, 78\% of $\mathrm{PwO}$ appreciated that their HCPs raised the subject of weight during their appointments (Fig. 3C). For PwO who did not discuss weight management with an HCP, fewer (45\%) thought they would have appreciated 
A

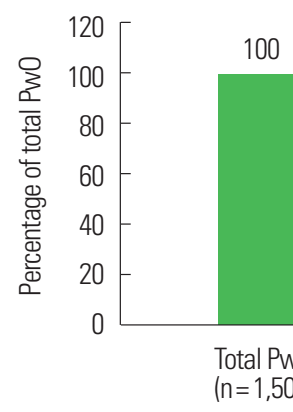

Proportion of PwO having weight management discussions, obesity diagnoses and follow-up appointment/calls
B

Time between when first started struggling with weight and had a weight management conversation with an $\mathrm{HCP}$

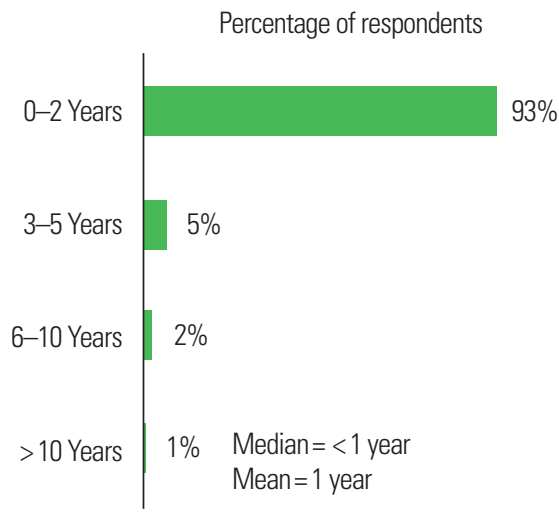

PwO who discussed weight with an HCP in the past 5 years; data calculated at respondent level from questions 0122 and $0122 \mathrm{~A}, \mathrm{n}=472$

D Feelings of Pw0 after weight management discussion
31

\begin{tabular}{ccc} 
& & 7 \\
& & 72 \\
\hline $\begin{array}{c}\text { scussed weight } \\
\text { in past } 5 \text { years } \\
(0120)\end{array}$ & Diagnosed with obesity & $\begin{array}{c}\text { Follow-up appointment/ } \\
\text { call related to weight } \\
\text { scheduled after last visit }\end{array}$
\end{tabular}

C Proportion of PwO who like or would like their HCP to raise the subject of weight during appointments

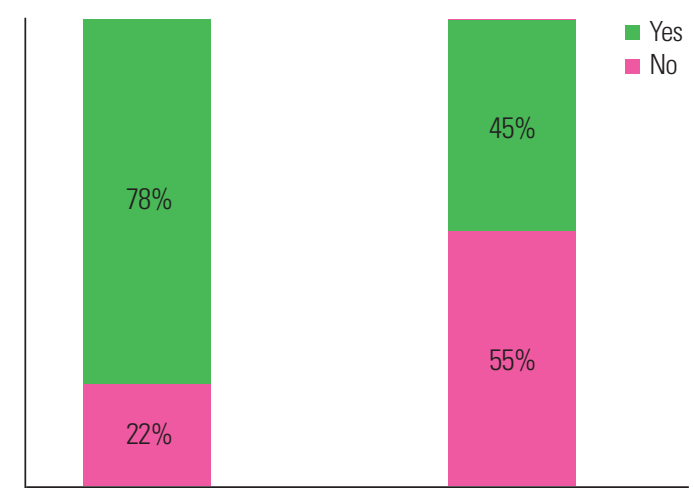

Like their HCP to raise the subject Would like their HCP to raise the of weight during appointments subject of weight during appointments

Among PwO, whose HCPs brought up the subject of weight during appointments $n=317 ; 0702$
Among PwO who did not discuss or among HCPs who did not bring up the subject of weight during appointments, $n=1,183 ; 0702$

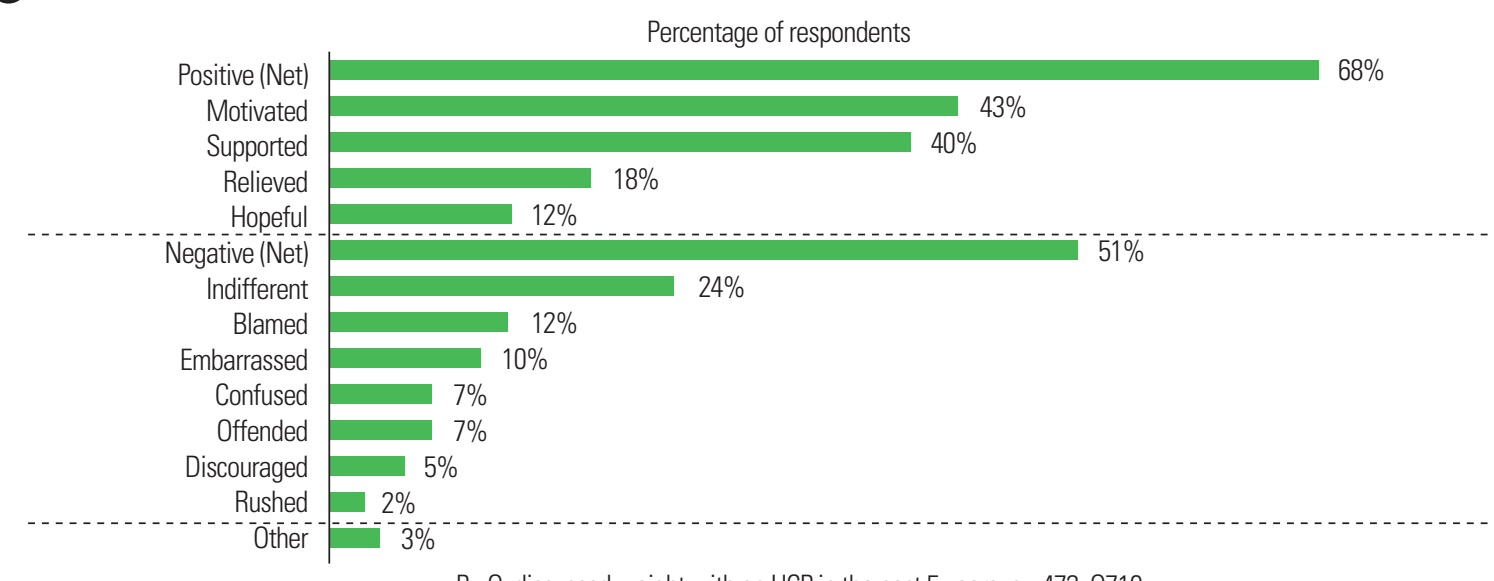

Pw0, discussed weight with an HCP in the past 5 years, $n=472 ; 0710$

Figure 3. Attitudes towards weight management discussions in Korea. (A) Proportion of people with obesity (Pw0) in Korea who reported: discussing weight with an healthcare professional (HCP) in the past 5 years, receiving a diagnosis of obesity, and having a follow-up appointment/call related to weight scheduled after their last visit with an HCP. (B) Length of time reported by PwO in Korea between the start of their struggles with weight and when they first had a weight management conversation with an HCP. (C) Proportion of PwO in Korea who like or would like their HCP to raise the subject of weight during appointments. (D) Feelings of PwO following the discussion of weight with an $\mathrm{HCP}$; more than one option could be selected. Q, survey question. 
their HCP raising the subject (Fig. 3C). Following a weight loss discussion, many $\mathrm{PwO}$ (68\%) reported positive feelings, while negative feelings were reported by a smaller proportion of $\mathrm{PwO}(51 \%)$, with $7 \%$ feeling offended by their discussion (Fig. 3D).

For $\mathrm{PwO}$, the top reason for not discussing weight management with an HCP was assuming full responsibility for managing their weight (PwO, 49\% vs. HCPs, 13\%) (Fig. 4). Limited appointment time was the principal reason selected by HCPs for not discussing weight with their patients (70\%), followed closely by $\mathrm{PwO}$ motivation (63\%; Fig. 4).

Reason for not discussing weight

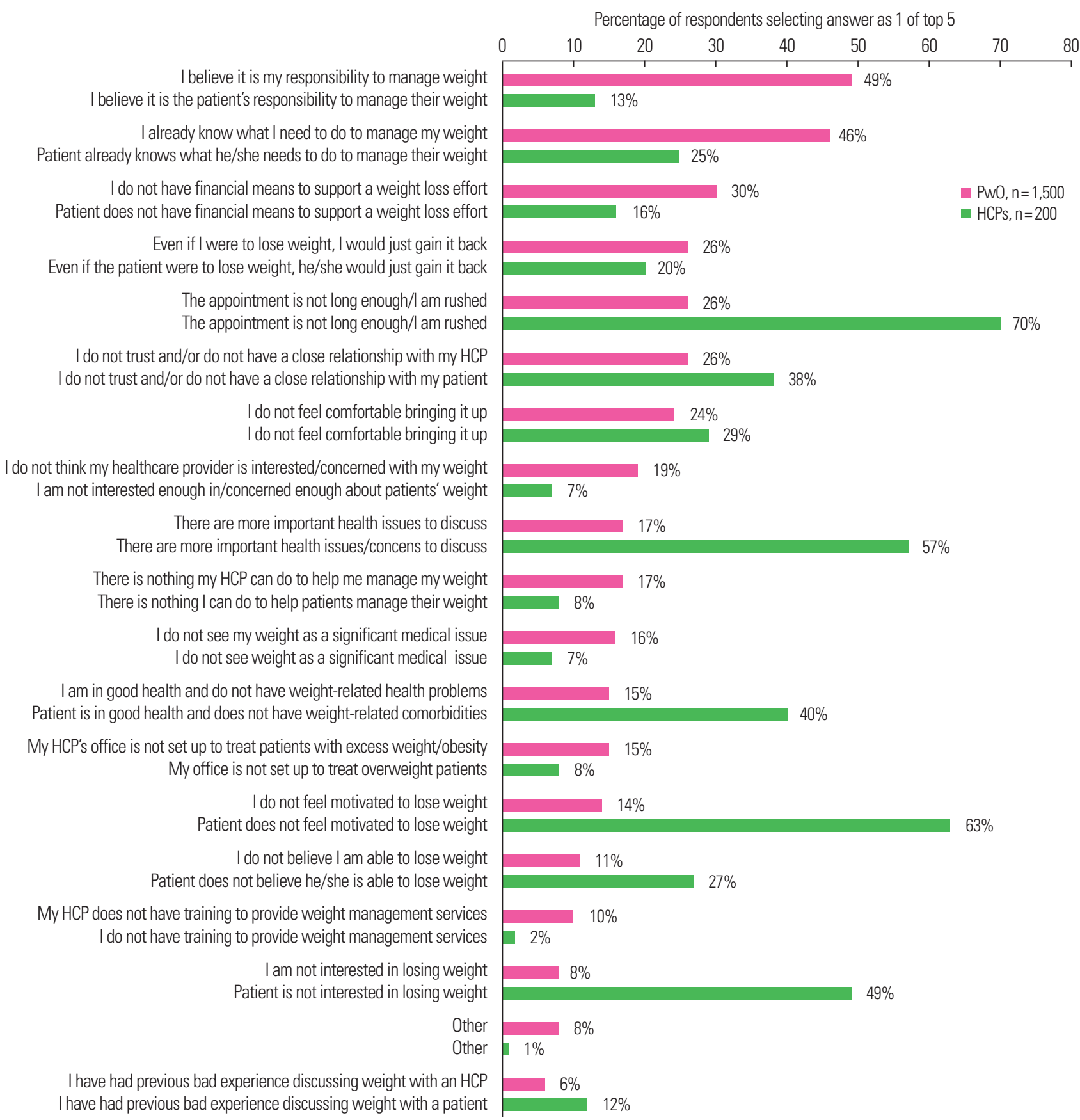

Figure 4. Reasons people with obesity (PwO) and healthcare professionals (HCPs) in Korea provided for not discussing weight with an HCP or patient, respectively. Respondents selected their top five reasons from the list of options presented on the X-axis. 


\section{Weight management strategies and goals}

General improvements in eating habits/calorie intake (65\%) and physical activity levels (51\%) were the methods most frequently recommended by HCPs for weight management (Supplementary Fig. 14). Other methods, including specific diet or exercise programs, weight loss medications, tracking, and bariatric surgery were less frequently considered during discussions. Referral to specialists as a weight management strategy was infrequently recommended by HCPs (Supplementary Fig. 14). There was agreement between most $\mathrm{PwO}$ and $\mathrm{HCPs}$ regarding the effectiveness of improving eating habits and increasing physical activity for weight management (Supplementary Fig. 15). However, more PwO (59\%) than HCPs (23\%) agreed that bariatric surgery was an effective method (Supplementary Fig. 15).

When deciding their goal weight loss, $50 \%$ of $\mathrm{PwO}$ set themselves an ambitious target that would require losing $>10 \%$ of their current body weight (overall mean 11.4\%) (Supplementary Fig. 16). On average, $\mathrm{PwO}$ reported receiving a recommended target of $17 \%$ body weight loss from HCPs (data not shown). The most frequently selected weight management goal was reducing the risks associated with excess weight or preventing a health condition (selected by $47 \%$ of $\mathrm{PwO}$ ), followed by losing any amount of weight (selected by $40 \%$ of $\mathrm{PwO}$ ) and improving existing health conditions (selected by $38 \%$ of PwO) (Supplementary Fig. 17).

\section{DISCUSSION}

South Korea's results from the ACTION-IO study highlighted several differences in the attitudes and perceptions expressed by $\mathrm{PwO}$ and HCPs towards obesity. Fewer HCPs than $\mathrm{PwO}$ agreed that obesity impacts overall health compared with other diseases like diabetes, stroke, cancer, or chronic obstructive pulmonary disease. Although most HCPs acknowledged that they are accountable for their patients' weight loss, the perception that obesity is not a serious disease might be preventing HCPs from promptly initiating weight management dialogue with their patients.

Most $\mathrm{PwO}$ assumed full responsibility for their weight management. Only a third felt that HCPs shared this burden. Due to this perception, $\mathrm{PwO}$ might not seek advice from their HCPs, thus preventing them from implementing effective weight loss methodolo- gies. Furthermore, their perceptions might also affect their preference for the source of information concerning weight management. South Korean $\mathrm{PwO}$ preferred information sources such as the internet or TV rather than seeking information from HCPs. The percentage of South Korean $\mathrm{PwO}$ who had discussed their weight with HCPs (31\%) was lower than that of the global population $(54 \%)^{5}$

The results from this study identified a misperception by HCPs of the weight loss efforts made by South Korean PwO. Although most $\mathrm{PwO}$ reported at least one serious weight loss attempt in the past, HCPs only recognized $35 \%$ of their patients as having made such attempts at controlling their weight, with $39 \%$ of these patients being successful. This lack of appreciation by HCPs may demotivate and discourage $\mathrm{PwO}$ from openly sharing their efforts. Consequently, PwO might approach other sources for weight management advice, which could be ineffective and may even pose significant risks to their health. HCPs should adopt an understanding and motivating attitude towards their patients' attempts at weight loss.

Of PwO who had discussed their weight with HCPs (albeit fewer than global $\mathrm{PwO}$ ), $\mathrm{PwO}$ from South Korea reported a shorter gap between recognizing their struggle with weight and initiating a weight management discussion with an HCP (1 year vs. 6 years for global $\mathrm{PwO}){ }^{5}$ Furthermore, the most frequently selected weight management goals by $\mathrm{PwO}$ were reducing the risks or health conditions associated with excess weight, suggesting concerns about health might prompt South Korean $\mathrm{PwO}$ to seek support from their HCPs.

Most $\mathrm{PwO}$ reported that $\mathrm{HCPs}$ initiated weight management conversations during their appointments. While the attitudes of $\mathrm{PwO}$ who had such conversations with their $\mathrm{HCP}$ were largely positive, more than half of those who had no weight discussions preferred their HCPs to not raise this issue. For these participants, initiating these conversations could be seen as unnecessary given that many South Korean $\mathrm{PwO}$ perceived that weight management is a personal responsibility.

Importantly, South Korean HCPs reported initiating weight loss discussions at a lower frequency than the global HCP cohort (52\% vs. $66 \%),{ }^{5}$ with the patient initiating the conversation $48 \%$ of the time in South Korea. Limited appointment time and the perception that their patients might not be motivated to lose weight were 
cited as the top reasons by HCPs from South Korea for not addressing weight. Although the influence of short appointment times was also evident in the global data, a lower proportion of global HCPs agreed with this reason (54\%). Alleviating certain administrative barriers to facilitate longer appointment times should be considered in South Korea.

Similar to the global population, both $\mathrm{PwO}$ and HCPs recognized unhealthy eating habits and lack of exercise as barriers to weight loss. ${ }^{5}$ However, South Korean PwO and HCPs shared differing opinions concerning the other hindrances to weight management: compared with HCPs, fewer $\mathrm{PwO}$ regarded their financial status and poor knowledge of obesity as barriers to weight loss. Similarly, PwO in South Korea placed little emphasis on genetics as a barrier to weight loss, despite scientific evidence suggesting otherwise. ${ }^{8,9}$ Efforts should be made to close these gaps in knowledge expressed by $\mathrm{PwO}$ in South Korea.

Limitations of this study include its cross-sectional and descriptive nature and reliance on accuracy of respondent recall. The selfreported height and weight could lead to underestimation of the BMI of respondents. The fairly low response rates, which can affect the sample representativeness, were consistent with similar surveybased studies. ${ }^{5}$

Overall, our data suggest that $\mathrm{PwO}$ and HCPs share a common perception that obesity is a chronic disease. This might enable both groups to be actively engaged in conversations about weight management and obesity care. The motivation of $\mathrm{PwO}$ for weight loss and their largely favorable responses towards initiation of weight discussions will be an opportunity for HCPs to be more actively involved in weight management discussions at their practice. Providing comprehensive education for $\mathrm{PwO}$ regarding weight management through reliable sources of information may diminish selfblame and motivate them in their weight loss journey. Our study also points to a demand for a systemic modification of the local healthcare system to lower the barriers for weight discussions.

\section{CONFLICTS OF INTEREST}

Soo Lim has received compensation for lecture fees from Astellas, AstraZeneca, Boehringer Ingelheim Korea Ltd., JW Pharmaceutical Corp, MSD Korea Ltd., Novartis, and Novo Nordisk. He serves as the editor-in-chief of the Journal of Obesity \& Metabolic Syndrome. Bumjo Oh has received compensation for lecture fees from Novartis and Novo Nordisk. Seung-Hwan Lee has received compensation from Novo Nordisk as a lecturer and consultant. Yousun Ha is an employee of Novo Nordisk. Jae-Heon Kang has received compensation from Novo Nordisk as a consultant and received funding for travel expenses to attend author meetings during the conduct of the study. Yang-Hyun Kim declares no conflict of interest.

\section{ACKNOWLEDGMENTS}

We thank the participants of the study. This study was sponsored by Novo Nordisk, which also provided financial support for medical editorial assistance from Ege Deniz Yildirim, $\mathrm{PhD}$ and Abbie Saunders, PhD, CMPP of Articulate Science, Ltd.

\section{AUTHOR CONTRIBUTIONS}

Study concept and design: JHK; analysis and interpretation of data: all authors; drafting of the manuscript: all authors; and critical revision of the manuscript: all authors.

\section{SUPPLEMENTARY MATERIALS}

Supplementary Table 1, Figures 1-17, and Supplementary materials (ACTION IO South Korea Data Report) can be found via https://doi.org/10.7570/jomes20013.

\section{REFERENCES}

1. NCD Risk Factor Collaboration (NCD-RisC). Trends in adult body-mass index in 200 countries from 1975 to 2014: a pooled analysis of 1698 population-based measurement studies with 19.2 million participants. Lancet 2016;387:1377-96.

2. Seo MH, Kim YH, Han K, Lee WY, Yoo SJ. Prevalence of obesity and incidence of obesity-related comorbidities in Koreans based on National Health Insurance Service Health Checkup Data 2006-2015 (J Obes Metab Syndr 2018;27:46-52). J Obes Metab Syndr 2018;27:198-9. 
3. Baik I. Forecasting obesity prevalence in Korean adults for the years 2020 and 2030 by the analysis of contributing factors. Nutr Res Pract 2018;12:251-7.

4. Seo MH, Lee WY, Kim SS, Kang JH, Kang JH, Kim KK, et al. 2018 Korean Society for the Study of Obesity Guideline for the Management of Obesity in Korea. J Obes Metab Syndr 2019;28:40-5.

5. Caterson ID, Alfadda AA, Auerbach P, Coutinho W, Cuevas A, Dicker D, et al. Gaps to bridge: misalignment between perception, reality and actions in obesity. Diabetes Obes Metab 2019; 21:1914-24.

6. Kim CS, Ko SH, Kwon HS, Kim NH, Kim JH, Lim S, et al. Prevalence, awareness, and management of obesity in Korea: data from the Korea national health and nutrition examination survey (1998-2011). Diabetes Metab J 2014;38:35-43.

7. International Society for Pharmacoepidemiology. Guidelines for good pharmacoepidemiology practices (GPP) [Internet]. Bethesda, MD: International Society for Pharmacoepidemiology; 2015 [cited 2020 Apr 26]. Available from: https://www. pharmacoepi.org/resources/policies/guidelines-08027/

8. Bray GA, Kim KK, Wilding JP; World Obesity Federation. Obesity: a chronic relapsing progressive disease process. A position statement of the World Obesity Federation. Obes Rev 2017;18:715-23.

9. Ghanemi A, Yoshioka M, St-Amand J. Broken energy homeostasis and obesity pathogenesis: the surrounding concepts. J Clin Med 2018;7:453. 